\title{
Alcoholic hypoglycemia as a result of acute challenges of ethanol
}

\author{
JAMES L. TRAMILL, PAUL E. TURNER, and GEORGE HARWELL \\ University of Southern Mississippi, Hattiesburg, Mississippi 39401 \\ and \\ STEPHEN F. DAVIS \\ Emporia State University, Emporia, Kansas 66801
}

\begin{abstract}
Alcohol-induced hypoglycemia was experimentally studied in male albino rats. Intraperitoneal injections of $30 \%$ ethanol resulted in a significant decrease in blood-sugar levels (relative to saline-injection control animals) in subjects that had fasted 48 and $72 \mathrm{~h}$. Alcohol-induced hypoglycemia was not found in nonfasted animals.
\end{abstract}

Hypoglycemia (low blood sugar) states have been recognized since 1849 , when Claude Bernard first discovered that the mobilization of liver glycogen was a source of blood sugar. In 1941, Brown and Harvey described hypoglycemia following the drinking of denatured alcohol solvents by six chronic alcoholics. Since that time, the clinical aspects of ethanol-induced hypoglycemia have been well documented (see DeMoura, Correia, \& Madeira, 1967; Freinkel, Singer, Arky, Bleicher, Anderson, \& Silbert, 1963; Neame \& Joubert, 1961). Based on experimental reproduction of this syndrome in human and animal subjects and on in vitro studies (e.g., Freinkel, Arky, Singer, Cohen, Bleicher, Anderson, Silbert, \& Foster, 1965; Madison, 1968; Madison, Lochner, \& Wulff, 1967), certain concepts about its pathogenesis have evolved. These concepts have typically focused on the dual factors of depleted hepatic glycogen stores and suppressed hepatic glycogenesis during ethanol oxidation.

Several studies (e.g., Field, Williams, \& Mortimore, 1963; Freinkel et al., 1963) demonstrated that the hypoglycemia potential of ethanol may be shown in normal human subjects via the interruption of fasting equilibrium by alcohol. Likewise, Bleicher, Freinkel, Byrne, and Seifert (1964) reported that ethanol can acutely lower blood sugar in the fasted dog. The Bleicher et al. (1964) data showed that .5 to $1.0 \mathrm{~g}$ of ethanol per kilogram of body weight resulted in hypoglycemia in dogs that had fasted from 4 to 8 days and hyperglycemia in dogs that had fasted for only 36 h. Klingman, Bane, and Haag (1959) obtained increases in the blood glucose of normal dogs following a single dose of ethanol. A report by Clark, Wilson, and Hulpieu (1961) concluded that a fasting period

Requests for reprints should be directed to James L. Tramill, Department of Instructional Services, Wichita State University, Wichita, Kansas 67208. was necessary but not sufficient to produce the alcoholhypoglycemia syndrome. Thus, based on cited reports, one would predict that a single injection of ethanol would result in an increase in blood-glucose levels in nonfasted subjects and a decrease in glucose levels in animals fasted for a period of days. This would be predicted because glycogen stores are depleted via fasting, with blood glucose subsequently being maintained by gluconeogenesis. Gluconeogenesis is depressed during alcohol metabolism, resulting in decreased glucose synthesis and hypoglycemia. Given this interpretation, one might further predict that extending the fasting periods could result in a greater decrease in blood-sugar levels.

As noted above, alcohol-induced hypoglycemia appears to be reasonably well documented in the pharmacological literature of the early 1960s. However, little research on this phenomenon has been reported in the psychological literature. This appears to be a rather salient omission in light of a recently proposed negative relationship between blood-sugar level and aggressive responding. Both field studies (Bolton, 1973, 1976; Bolton \& Vadheim, 1973) and experimental studies in which blood-sugar levels were reduced via insulin injections (Davis, Cronin, Meriwether, Neideffer, \& Travis-Neideffer, 1978; Davis, Gussetto, Tramill, Neideffer, \& TravisNeideffer, 1978; Neideffer, Travis, Davis, Voorhees, \& Prytula, 1977) have lent support to this proposed relationship. Thus, the purpose of the present study was to initiate experimental investigators into the alcohol-induced hypoglycemia syndrome.

\section{METHOD}

\section{Subjects}

Thirty-six male Sprague-Dawley rats served as subjects. The animals were approximately 180 days old at the time of testing and were individually caged, with food and water freely available. 


\section{Procedure}

At the beginning of the experiment, the subjects were assigned randomly to one of six equal groups $(n=6)$ : NF-S (nonfast, saline), NF-A (nonfast, alcohol), 48-S (48-h fast, saline), 48-A (48-h fast, alcohol), 72-S (72-h fast, saline), and 72-A (72-h fast, alcohol). Groups NF-S and NF-A had food freely available until time of injection, Groups 48-S and 48-A had all food removed from their cages $48 \mathrm{~h}$ prior to injection, and Groups 72-S and 72-A had all food removed $72 \mathrm{~h}$ before injection. Prior to injection, all animals were weighed, and injection amounts were determined by the ratio of $.25 \mathrm{cc}$ solution per $100 \mathrm{~g}$ of body weight. Groups NF-S, 48-S, and 72-S all received intraperitoneal injections of a $.9 \%$ isotonic saline solution $2 \mathrm{~h}$ prior to testing. Groups NF-A, 48-A, and 72-A received intraperitoneal injections of a saline-alcohol mixture containing $30 \%$ ethanol $(591.75 \mathrm{mg}$ ethanol $/ \mathrm{kg}$ body weight) $2 \mathrm{~h}$ prior to testing. The order of subject injection, and hence the order for testing, was randomly determined.

Using the tail-snip technique, as described by Woods, Makous, and Hutton (1969), approximately $50 \mu \mathrm{l}$ of whole blood were collected $2 \mathrm{~h}$ after the appropriate injection from each subject in heparinized capillary tubes (to prevent clotting). The filled capillary tubes were placed in a microcapillary centrifuge for $5 \mathrm{~min}$ $(10,000 \mathrm{~g})$ in order to separate the blood plasma. The plasma $(10 \mu \mathrm{l})$ was then analyzed by a Beckman glucose analyzer (Model ERA-2001). The glucose analyzer was calibrated and rechecked after each 12th sample by a normal-value standard and after each 4th sample by either Dade Monitrol I normal or abnormal serum assay controls. All checks were within recommended limits.

\section{RESULTS}

Data from the Beckman glucose analyzer were analyzed using a 2 by 3 factorial analysis of variance. Mean glucose levels $(\mathrm{mg} / 100 \mathrm{ml})$ are shown in Figure 1. The effect of duration of fasting (sated vs. 48-h fast vs. 72-h fast) was found to be significant $[\mathrm{F}(2,30)=34.75, \mathrm{p}<.001]$. Subsequent comparisons, performed by the Newman-Keuls procedure, indicated that the blood-glucose level of the nonfasted subjects was significantly higher $(p<.01)$ than that of the subjects in either of the fasted con-

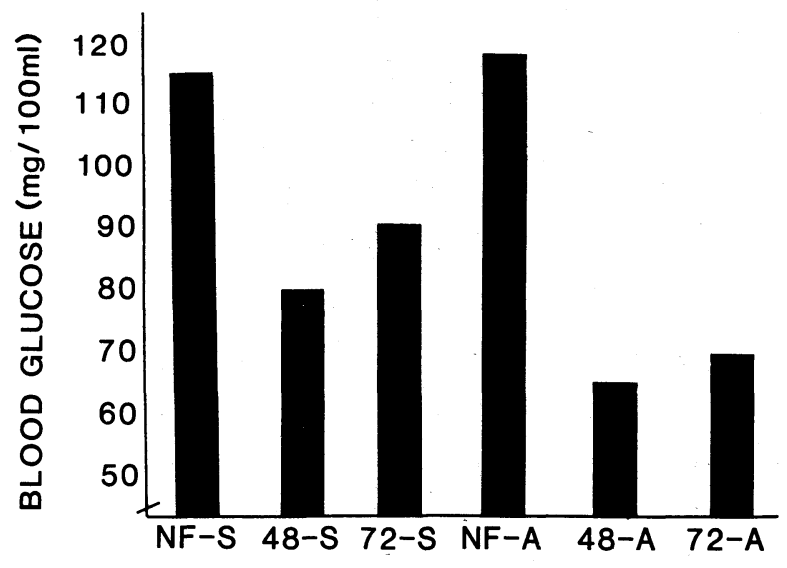

TREATMENTS

Figure 1. Mean blood glucose levels. ditions. In turn, nonsignificant differences were found between the 48-h and 72-h fasted groups.

The effect of saline vs. alcohol injections was also found to be significant $[F(1,30)=6.77, p<.02]$, with lowered blood-sugar levels being found in the alcoholinjected subjects. The interaction effect was found to be nonsignificant $[F(2,30)=2.22, \mathrm{p}>.10]$.

To ascertain the validity of the predicted hypotheses, simple main effects analyses were employed. Comparisons of Groups NF-S and NF-A failed to support the prediction of increased glucose levels in nonfasted animals $[F(1,30)=.04, p>.25]$. Significant contrasts between Groups 48-S and 48-A $[F(1,30)=4.22, \mathrm{p}<.05]$ and Groups $72-\mathrm{S}$ and 72-A $[F(1,30)=6.95, p<.05]$ lent support to the hypothesized decrease in blood-sugar levels due to alcohol injections in the fasted animals. The lack of significance between Groups 48-A and 72-A $[\mathrm{F}(1,30)=.47$, $\mathrm{p}>.25$ ] indicated that increasing fasting from 48 to $72 \mathrm{~h}$ failed to result in changes in blood-sugar level.

\section{DISCUSSION}

The results of the present study indicate that an acute challenge of a moderate amount of ethanol can induce a hypoglycemic state in the fasted white rat. Some interesting questions concerning the parameters of this phenomenon are also prompted by these data.

Madison (1968) concluded that alcohol-induced hypoglycemia was a function of the dual factors of depleted hepatic glycogen stores and suppression of hepatic glycogenesis during ethanol oxidation. Madison's (1968) conclusions raise two issues concerning the results of the present study. First, these conclusions would lead to an expectation of greater decreases in blood-sugar levels resulting from longer periods of food deprivation. Second, if alcohol hypoglycemia is a function of the suppression of hepatic glycogenesis during ethanol oxidation, one might well speculate that larger doses of ethanol would lead to a greater physiological basal effect.

The lack of significant differences between Groups 48-A and 72-A suggests that the expectation of greater decreases in blood-sugar levels resulting from longer fasting periods may not be tenable for the specific fasts employed in the present study. This nonsignificant difference could possibly be related to a physiological basal effect for depletion of hepatic glycogen stores for periods of 48 to $72 \mathrm{~h}$. If this is the case, then longer fasting periods might well lead to greater decreases in blood-sugar levels as a function of ethanol injections.

Concerning the prediction that larger doses of ethanol might result in a greater physiological basal effect (i.e., greater decreases in blood-sugar level), the present data are obviously not sufficient to allow 
direct commentary. However, a recent study by Wesley and Tramill (Note 1) has yielded supportive data. In this study, groups of rats experiencing a restricted feeding regimen ( $80 \%$ free-feeding body weight) were injected with solutions containing $0 \%, 25 \%$, and $50 \%$ ethanol, respectively, for 14 days. The results indicated that the subjects injected with the $50 \%$ ethanol solution had significantly lower blood-sugar levels than did the $0 \%$ and $25 \%$ animals. In turn, the $25 \%$ animals had significantly lower blood-glucose levels than did the $0 \%$ animals.

A third area for future investigations lies in the time period utilized between injection and the taking of the blood sample. The time interval of $2 \mathrm{~h}$ used in the present study, although based on previous pilot studies and a review of the literature, was still a somewhat arbitrary decision. The actual time of greatest decrease in blood-sugar levels may well occur before or after the 2 -h interval used in the present study. Only future studies will resolve this issue.

\section{REFERENCE NOTE}

1. Wesley, A. J., \& Tramill, J. L. Aggressive responses to chronic injections of ethanol reflect a dose dependent relationship. Paper presented at the meeting of the Southwestern Psychological Association, Oklahoma City, 1980.

\section{REFERENCES}

Bernard, C. Comptes rendus des Séances de la Société de Filiaies et de Fes Biologie, 1849, 1, 121.

Bleicher, S. F., Freinkel, N., Byrne, J. J., \& Seifert, D. Effect of ethanol on plasma glucose and insulin in the fasted dog. Proceedings of the Society for Experimental Biology and Medicine, 1964, 115, 369-373.

Bolton, R. Aggression and hypoglycemia among the Qolla: A study in psychobiological anthropology. Ethnology, 1973, 12, 222-257.

Bolton, R. Hostility in fantasy: A further test of the hypoglycemiaaggression hypothesis. Aggressive Behavior, 1976, 2, 257-274.

Bolton, R., \& Vadheim, C. The ecology of East African homicide. Behavior Science Notes, 1973, 8, 319-341.

Brown, T. M., \& Harvey, A. M. Spontaneous hypoglycemia in "smoke" drinkers. Journal of the American Medical Association, 1941, 117, 12-15.

Clark, W. C., Wilson, J. E., \& Hulpieu, H. R. Production of hypoglycemia by Solox and by ethanol. Quarterly Journal of Studies on Alcohol, 1961, 22, 365-373.

Davis, S. F., Cronin, E. L., Meriwether, J. A., Neideffer, J., \& Travis-Neideffer, M. N. Shock-elicited attack and biting as a function of chronic vs. acute insulin injection. Bulletin of the Psychonomic Society, 1978, 12, 149-151.

Davis, S. F., Gussetto, J. K., Tramill, J. L., Neideffer, J., \& Travis-Neideffer, M. N. The effects of extended insulin dosage on target-directed attack and biting elicited by tailshock. Bulletin of the Psychonomic Society, 1978, 12, 80-82.

DeMoura, M. C., Correia, J. P., \& Madeira, F. Clinical alcohol hypoglycemia. Annals of Internal Medicine, 1967, 66, 893-905.

Field, J. B., Williams, H. E., \& Mortimore, G. E. Studies on the mechanism of ethanol-induced hypoglycemia. Journal of Clinical Investigation, 1963, 42, 497-506.

Freinkel, N., Arky, R. A., Singer, D. L., Cohen, A. K., Bleicher, S. J., Anderson, J. B., Silbert, C. K., \& Foster, A. E. Alcohol hypoglycemia. IV. Current concepts of its pathogenesis. Diabetes, 1965, 14, 350-361.

Freinkel, N., Singer, D. L., Arky, R. A., Bleicher, S. F., Anderson, J. B., \& Silbert, C. K. Alcohol hypoglycemia. I. Carbohydrate metabolism of patients with clinical alcohol hypoglycemia and the experimental reproduction of the syndrome with pure ethanol. Journal of Clinical Investigation, 1963, 42, 1112-1113.

Klingman, G. K., Bane, R., \& HaAg, G. B. Studies on severe alcohol intoxication in dogs. III. Effect of adrenalectomy. Quarterly Journal of Studies on Alcohol, 1959, 20, 13-23.

Madison, L. L. Ethanol-induced hypoglycemia. Advances in Metabolic Disorders, 1968, 3, 85-109.

Madison, L. L., Lochner, A., \& Wuff, J. Ethanol-induced hypoglycemia. II. Mechanism of suppression of hepatic gluconeogenesis. Diabetes, 1967, 16, 252-258.

Neame, P. B., \& Joubert, S. M. Postalcoholic hypoglycemia and toxic hepatitis. Lancet, 1961, 2, 893-897.

Neideffer, J., Travis, M. N., Davis, S. F., Voorhees, J. W., \& Prytula, R. E. Sweet and sour rats: The effect of insulin dosage on shock-elicited aggression. Bulletin of the Psychonomic Society, 1977, 10, 311-312.

Woods, S. C., Makous, W., \& Hutton, R. A. Temporal parameters of conditioned hypoglycemia. Journal of Comparative and Physiological Psychology, 1969, 69, 301-307.

(Received for publication December 10, 1979; revision accepted October 16, 1980.) 